\title{
Management of Organizational and Technological Risks at the Stage of Preparation in Order to Minimize the Cost of Construction Activities
}

Bojan Marković ${ }^{1}$

${ }^{1} \mathrm{PhD}$ Student, Department for Postgraduate studies, Singidunum University, Belgrade, Serbia

\begin{abstract}
.
Construction industry all-around is vulnerable to socio-economic occurrences transpiring both globally and locally, which negatively impact the basic objectives of projects - time, quality and cost. With ever-growing possibilities of entering new markets, and new companies emerging from previously undeveloped countries, the contest for high profile and lucrative projects sharpens. The effectiveness and competitiveness of a construction company depends on its ability to withstand the influence of many disturbing factors of external and internal environments. Whether their roots are in external causes or internal causes, they appear at all stages of construction projects bringing the need to hire experts to tackle them. To mitigate these negative effects proper risk management techniques need to be applied to various construction activities, and out of years of scientific and field research it is determined that the most important ones are those that occur in the stage of preparation of a project. Delays which come out of improper realization of that stage result in increasing costs during the construction activities - therefore the amount of funding necessary for completing the project usually significantly increases, since the quality of the finished object must be as contracted. This paper presents an internal comparative analysis of losses caused by the effects of organizational and technological risks in construction of multiple residential buildings for which there wasn't proper analysis of construction activities in preparation stage. Given analysis shows that there is a need to improve organizational and technological consciousness about the stage of construction preparation.
\end{abstract}

Keywords: construction management, risk management, risk assessment, construction delays, mitigating risks 


\section{Introduction}

Construction projects have a reputation for going out of planned budget and timeframe and yet many companies still do not invest into project risk and change management which should be a core component of project controls. Moreover, they employ people on executive positions which do not properly understand what risk is and which are risk management activities and therefore cannot truly comprehend why their project wasn't successful. Today's project managers are facing multiple challenges through the entire project lifecycle in unclear goals, ineffective communication, inaccurate time and cost estimates, poor risk management and unrealistic deadlines which can be set by investor, their employer or by themselves. Also, in today's society the challenge of reducing the effects on the environment and the environmental protection during the construction activities puts additional stress on them. All of that amounts to the cost of finished project.

Most construction project managers focus on management of changes that appear in later processes of Project Execution and Project Closedown of the project management process while in the early processes like Project Initiation and Project Planning they do not do any analysis' of possible risks which invoke those changes later on. In the Project Planning phase (which is the stage of preparation for the construction industry project) where the Contractor has possibilities to make estimations that would lead a project to its successful finish, a project manager working for Contractor must provide a comprehensive analysis of possible risks to increase the stability of the process of construction activities.

One of the most important areas of increasing the stability of the process of construction activities is to reduce the organizational and technological risks. Since construction activity is always easily put off tracks due to various emerging factors trough construction period, it increases the growth of organizational risks that affect the increment of costs of construction projects due to the costs of restoring organizational failures. The emerging factors (if not foreseen in advance) often require the coordination of the parameters of the following construction processes with the flows of failures and high costs of their restoration.

The object of the paper is the organizational and technological risks, random factors of uncertainty of construction projects during the stage of preparation for construction activities in residential buildings construction, especially in the area of influencing the environment during the period of construction activities and the increase of costs coming out of it. On the basis of the analysis of different costs types during construction activities from a survey of the process of construction works of 40 residential buildings in three major cities in Serbia, the task was to show the usual organizational structure of construction companies in Serbia led to increase in cost of construction projects, and to increase the reliability of planning process at the stage of preparation for the construction activities. 


\section{Material and Methodology}

\subsection{Risk and Project Risk Management}

Risk is considered as an event of any type of human action carried out in unfavourable conditions with the potential to have negative consequences on the project. It usually reduces chances for delivering a project's defined scope on time and within budget. The average estimate of the sum of evens that can cause a risk $R_{c}$ is determined in a following way:

$$
\mathrm{R}_{\mathrm{c}}=\sum_{\mathrm{i}=\mathrm{i}}^{\mathrm{t}} \sum_{\mathrm{i}=\mathrm{i}}^{\mathrm{p}} \sum_{\mathrm{i}=1}^{\mathrm{k}} \mathrm{R}_{\mathrm{ri}} * \mathrm{M}_{\mathrm{ri}}
$$

where we have $\mathrm{R}_{\mathrm{ri}}$ as individual risk events; $\mathrm{M}_{\mathrm{ri}}$ as the costs of their occurrences; and $\mathrm{t}, \mathrm{p}, \mathrm{k}$ as the number of events at the appropriate stages of a project [4]. From the formula it is seen that if the project manager does not pay enough attention to the study and analysis of risks they can easily increase the cost of a project.

Project risk management is a continuous process of managing those events by identifying, analysing, prioritising and mitigating risks that threaten a projects chance of success in terms of cost, schedule, quality, safety and technical performance. It has traditionally worked in three directions: preventing the danger of environmental and property risks; looking for opportunities to prevent and manage the negative effects of risk and forming an effective project management framework which nullifies risks and changes while bring benefits to the project.

\subsection{Risks in a Construction Industry}

In construction industry, factors affecting the type of risk from a point of a construction company can be divided into two groups: objective or uncontrollable risks which are inflation, competition, economic and political crises, weather conditions, design decisions; and subjective or controllable risks which appear as a result of construction potential, technical equipment, organization of construction activities and labour, safety standards, etc. 
Figure 1: Classification of the main risks in construction

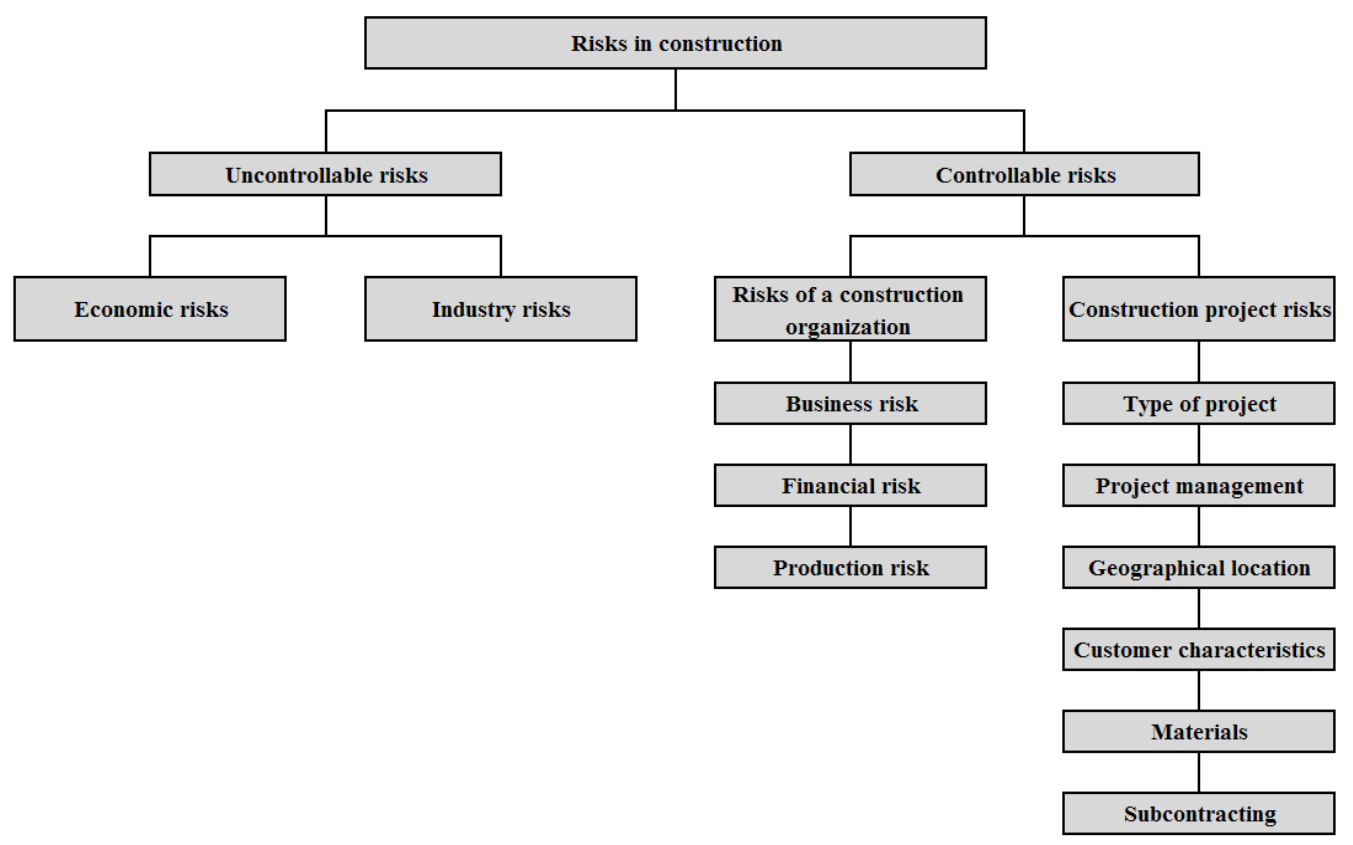

In any commercial project, including in the process of building construction and facilities, it is necessary to identify and classify risks and for construction activity the most important are those that occur from the internal source since most of them can be predicted ahead of time and mitigated with proper management activities. They can be objective (unforeseen changes in the construction process (failure of technology, its moral aging); natural disasters; unforeseen changes in internal relations; financial problems within the company and lack of motivation mechanism) and subjective factors (low quality of management, workers and specialists; incompetent management and other services; non-compliance with contracts by the company; lack of staff's ability to tackle risks; errors in decision making; errors in the implementation of risky decisions and death or illness of leading employees).

\subsection{Organizational and Technological Factors Affecting the Risks of Construction Activities}

The factors of intensity of construction activities from the point of view of their influence on the profit of the organization are divided into two groups: factors stimulating an increase in the intensity of construction activities, that is, reducing construction time (approaching the time of planned finish date; reducing the terms of borrowed loans, which reduces interest rates and interest payments; reduction of production costs, mainly due to overhead costs, the magnitude of which is proportional to the duration of the construction; reduction of loss of lost opportunities due to the use of released capacities on other projects); and factors that stimulate a decrease in the intensity of conducting activities and increase the duration of construction (concentration of equipment at the construction site, which gives 
increased costs for management, organization of work, security of the site; the need for large amounts of financing during the peak period of construction; increased financial losses in case of possible disruptions and stops the construction process)[7].

\subsection{Cost of Construction Activities}

The organizational and technological factors affecting the risks in construction projects are most appropriate to evaluate through the structure of the cost of construction activities, which are one of the most important indicators of the economic efficiency of construction [3].

The total cost of construction production consists of costs for construction and installation works on the erection of buildings and structures, installation of technological equipment; the acquisition of basic and auxiliary technological equipment, as well as other costs (research and development, design and development work, preparatory work, overhead, maintenance of the directorate, etc.).

Without entering into detailed discussion the total cost $\mathrm{C}$ of construction activities is derived from the previous statement:

$$
\mathrm{C}=\mathrm{C}_{\mathrm{ca}}+\mathrm{C}_{\mathrm{sw}}+\mathrm{C}_{\mathrm{oc}}+\mathrm{C}_{\mathrm{r}}-\mathrm{S}
$$

where $\mathrm{C}_{\mathrm{ca}}$ represents the cost of construction activities, $\mathrm{C}_{\mathrm{sw}}-$ secondary works, $\mathrm{C}_{\mathrm{oc}}$ are other costs and $\mathrm{C}_{\mathrm{r}}$ come from risks and their unsuccessful mitigation. $\mathrm{S}$ is the reduction of cost created by successful construction project management [1][2].

When analyzing the structure and composition of the estimated cost of construction activities, we can conclude that the main organizational and technological factors causing risks affect the change in two cost groups: direct costs and overhead costs. Direct costs are determined on the basis of the physical volume of work, structural solutions of constructions, accepted methods of production technology, work methods of construction and installation; based on unit prices for certain types of work. Among the overhead costs, a conditionally constant part is distinguished, which mainly depends on the duration of the construction: the cost of maintaining administrative and maintenance personnel; security and lighting of the construction site, etc. The planned savings (estimated profit) include the deduction of funds to cover the expenses of the construction organization, not passing through the direct costs and overhead costs.

Table 1: Approximate structure of the estimated cost of construction activities by type, \%

\begin{tabular}{|l|c|}
\hline Cost Types & Total expenses, $\%$ \\
\hline 1. Direct costs & $75-80$ \\
Including: & $20-35$ \\
-basic wage of workers & $46-50$ \\
-cost of materials & $15-20$ \\
\hline -operation of construction machinery and equipment & $12-18$ \\
\hline 2. Overhead costs & $5-8$ \\
\hline 3. Planned savings or estimated profits & \\
\hline
\end{tabular}

As seen from the previous, risks can introduce significant costs into construction projects if not recognized and analyzed properly and on time. 


\subsection{Basis for Quantitative Assessment of Project Risks}

Projects for the residential buildings presented in the paper have taken places in four cities in Serbia from 2016. to 2019. and each project was done by a different company. The data was acquired by interview questioners directly from the site managers of construction companies, or in some cases from investors, architectural firms. For some projects it was impossible to acquire the exact data for the additional costs because the companies didn't kept records, they gave approximate percentage of possible distribution of them among the types of costs. Construction activities include only construction works without installation works. Smaller scale projects (up to 3000sqm) were done exclusively by small and middle sized Serbian companies of local origin; mainly characterised as manufacturing firm with the mix of engineering. All of them utilised the knowledge of one engineer, usually with less than three years of experience and following multiple construction sites simultaneously, while at some the owner had engineering degree. Most of the main decisions fell on the leading specialised workers on the site, which made organizational structure of the firm irregular or nonexistent and it caused many organizational problems. Larger scale projects (over 3000sqm) were mostly done by engineering and construction companies specialised for constructing residential buildings with a mixed organizational structure; some of them were foreign with their foreign department Serbia - Austrian, Italian, German, Turkish, Israeli and Bulgarian. In their organization they employed a large number of engineers divided into departments among which were: Procurement Department, Engineering Department, Production Department and Commercial Department. The project management was a job for Engineering Department which had at least one project manager which run several projects in cooperation with site managers.

\subsection{Quantitative Assessment of Organizational and Technological Risks Reflected in the Cost Groups of Construction Activities}

A quantitative assessment of the organizational and technological risk factors reflected in the construction costs groups was carried out on the basis of the method of analogies or conservative forecasts - study of lessons learned on similar projects to calculate the likelihood of loss (risk assessment of often recurring projects). When assessing risks trough the cost, the entire surveyed population of residential buildings was divided into four groups, based on approximately equal cost of construction activities and according to the construction price per square metre: group A up to 2000sqm, B up to 3000 sqm, C up to 5000 sgm and D up to 8000 sqm (Table 3).

\begin{tabular}{|c|c|c|c|c|c|c|c|c|}
\hline \multirow{3}{*}{ 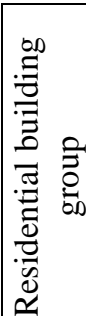 } & \multirow[b]{3}{*}{ 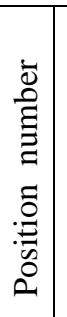 } & \multirow[b]{3}{*}{$\begin{array}{c}\text { Planned } \\
\text { construction } \\
\text { cost (budget) }\end{array}$} & \multirow[b]{3}{*}{$\begin{array}{c}\text { Cost of } \\
\text { construction } \\
\text { activities }\end{array}$} & \multicolumn{5}{|c|}{ Cost of construction activities by type } \\
\hline & & & & \multicolumn{3}{|c|}{ Direct costs } & \multirow[b]{2}{*}{$\begin{array}{l}\text { Overhead } \\
\text { costs }\end{array}$} & \multirow[b]{2}{*}{$\begin{array}{l}\text { Costs from } \\
\text { the effects } \\
\text { on the } \\
\text { environmen }\end{array}$} \\
\hline & & & & $\begin{array}{l}\text { The main } \\
\text { salary of } \\
\text { workers }\end{array}$ & $\begin{array}{c}\text { Material } \\
\text { costs }\end{array}$ & $\begin{array}{l}\text { Operating } \\
\text { costs of } \\
\text { machinery } \\
\text { and } \\
\text { equipment }\end{array}$ & & \\
\hline
\end{tabular}


$3^{\text {rd }}$ International Conference On Research In MANAGEMENT AND ECONOMICS

\begin{tabular}{|c|c|c|c|c|c|c|c|c|}
\hline 1 & 2 & 3 & 4 & 5 & 6 & 7 & 8 & 9 \\
\hline \multirow{12}{*}{ A } & 1 & 865190 & 980155 & 205832 & 470474 & 127420 & 127420 & 49008 \\
\hline & 2 & 882377 & 945701 & 208054 & 416108 & 113484 & 141855 & 66199 \\
\hline & 3 & 911328 & 969462 & 193892 & 445953 & 116335 & 135725 & 77557 \\
\hline & 4 & 962457 & 956690 & 198991 & 420943 & 121500 & 133937 & 81319 \\
\hline & 5 & 829867 & 989318 & 207757 & 445193 & 128611 & 148398 & 59359 \\
\hline & 6 & 939843 & 942847 & 193284 & 433710 & 122570 & 150856 & 42428 \\
\hline & 7 & 886411 & 962827 & 211809 & 433246 & 105905 & 154043 & 57824 \\
\hline & 8 & 948553 & 963245 & 214804 & 416122 & 105957 & 163752 & 62611 \\
\hline & 9 & 890969 & 973700 & 230767 & 457931 & 107107 & 107107 & 70788 \\
\hline & 10 & 975025 & 994308 & 203833 & 424570 & 129260 & 169032 & 67613 \\
\hline & 11 & 877011 & 974627 & 231961 & 458075 & 126702 & 107209 & 50681 \\
\hline & $\mathrm{A}$ & 906275 & 968444 & 209180 & 438393 & 118623 & 139939 & 62308 \\
\hline \multirow{9}{*}{ B } & 1 & 1485617 & 1485314 & 331225 & 656509 & 185664 & 237650 & 74266 \\
\hline & 2 & 1425020 & 1506980 & 346605 & 649508 & 206456 & 213991 & 90419 \\
\hline & 3 & 1351192 & 1490095 & 323351 & 610939 & 230965 & 235435 & 89406 \\
\hline & 4 & 1489876 & 1511398 & 377850 & 619673 & 211596 & 196482 & 105798 \\
\hline & 5 & 1284472 & 1479348 & 310663 & 680500 & 184918 & 229299 & 73967 \\
\hline & 6 & 1288170 & 1522771 & 347192 & 642624 & 213188 & 213188 & 106580 \\
\hline & 7 & 1421640 & 1492375 & 316383 & 671569 & 208932 & 220871 & 74619 \\
\hline & 8 & 1458516 & 1544031 & 370567 & 676286 & 208444 & 211532 & 77202 \\
\hline & A & 1400563 & 1504039 & 340480 & 650951 & 206271 & 219806 & 86532 \\
\hline \multirow{12}{*}{$\mathrm{C}$} & 1 & 2153300 & 2406518 & 536654 & 1061275 & 344132 & 320067 & 144391 \\
\hline & 2 & 2672573 & 2447206 & 499230 & 1174659 & 330373 & 293665 & 149280 \\
\hline & 3 & 2493070 & 2404860 & 529069 & 1058139 & 288583 & 360729 & 168340 \\
\hline & 4 & 2423848 & 2421513 & 477038 & 1094524 & 317233 & 358384 & 174334 \\
\hline & 5 & 2608071 & 2389652 & 549620 & 1029940 & 327382 & 339331 & 143379 \\
\hline & 6 & 2321091 & 2438867 & 536551 & 1097490 & 268275 & 390219 & 146332 \\
\hline & 7 & 2257877 & 2361569 & 536076 & 1091045 & 276304 & 283388 & 174756 \\
\hline & 8 & 2579409 & 2394624 & 569921 & 1125473 & 311301 & 263409 & 124520 \\
\hline & 9 & 2603208 & 2417948 & 507769 & 1112256 & 302244 & 374782 & 120897 \\
\hline & 10 & 2509728 & 2375295 & 570071 & 1040379 & 320665 & 325415 & 118765 \\
\hline & 11 & 2376407 & 2409319 & 602330 & 983002 & 375854 & 313211 & 134922 \\
\hline & $\mathrm{A}$ & 2454417 & 2406125 & 537666 & 1078926 & 314759 & 329327 & 145447 \\
\hline \multirow{11}{*}{$\mathrm{D}$} & 1 & 4076174 & 3837294 & 798157 & 1765155 & 594781 & 487336 & 191865 \\
\hline & 2 & 3623327 & 3836474 & 805660 & 1734086 & 529433 & 545471 & 191824 \\
\hline & 3 & 4147166 & 3870760 & 855438 & 1718618 & 503199 & 599968 & 193538 \\
\hline & 4 & 3706611 & 3823378 & 860260 & 1624936 & 497039 & 573507 & 267636 \\
\hline & 5 & 4120653 & 3884449 & 912846 & 1837345 & 466134 & 466134 & 201991 \\
\hline & 6 & 3908669 & 3836611 & 759649 & 1730311 & 510269 & 560145 & 276236 \\
\hline & 7 & 3727181 & 3868872 & 789250 & 1818370 & 522298 & 502953 & 236001 \\
\hline & 8 & 4064663 & 3858998 & 906865 & 1643933 & 490093 & 586568 & 231540 \\
\hline & 9 & 3641096 & 3873845 & 929723 & 1611519 & 615941 & 503600 & 213061 \\
\hline & 10 & 3811383 & 3863924 & 917522 & 1623433 & 575982 & 554836 & 192151 \\
\hline & A & 3882692 & 3854520 & 846427 & 1720475 & 465987 & 539520 & 282111 \\
\hline
\end{tabular}

\subsection{Losses and Gains Caused by the Effects of Organizational and Technological Risks}

If we want to analyze influence of improper and proper construction risk management on individual types of cost it is necessary to calculate every cost separately and to analyze 


\section{MANAGEMENT AND ECONOMICS}

their dependency. That way it is possible to focus more on the one that has the most influence on the project in future planning. In the following table (Table 4) are given the amounts of cost that went over or under planned amount, with positive numbers being the additional costs.

Table 4: Additional cost structure of construction activities of surveyed residential buildings, $€$

\begin{tabular}{|c|c|c|c|c|c|c|}
\hline \multirow{3}{*}{ 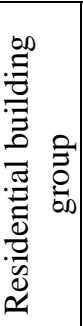 } & \multirow[b]{3}{*}{ 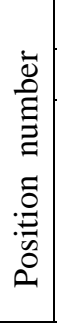 } & \multicolumn{5}{|c|}{ Additional cost of construction activities by type } \\
\hline & & \multicolumn{3}{|c|}{ Direct costs } & \multirow[b]{2}{*}{ Overhead costs } & \multirow[b]{2}{*}{$\begin{array}{l}\text { Costs from the } \\
\text { effects } \\
\text { on the } \\
\text { environment }\end{array}$} \\
\hline & & $\begin{array}{c}\text { The main salary } \\
\text { of workers }\end{array}$ & Material costs & $\begin{array}{c}\text { Operating costs of } \\
\text { machinery and } \\
\text { equipment }\end{array}$ & & \\
\hline 1 & 2 & 3 & 4 & 5 & 6 & 7 \\
\hline \multirow{12}{*}{ A } & 1 & 21886 & 29589 & 16652 & 8642 & 38196 \\
\hline & 2 & 12055 & 16298 & 9172 & 4760 & 21039 \\
\hline & 3 & 11067 & 14962 & 8420 & 4370 & 19315 \\
\hline & 4 & -1098 & -1484 & -835 & -434 & -1916 \\
\hline & 5 & 30354 & 41038 & 23095 & 11986 & 52976 \\
\hline & 6 & 572 & 773 & 435 & 226 & 998 \\
\hline & 7 & 14547 & 19667 & 11068 & 5744 & 25389 \\
\hline & 8 & 2797 & 3781 & 2128 & 1104 & 4881 \\
\hline & 9 & 15749 & 21293 & 11983 & 6219 & 27487 \\
\hline & 10 & 3671 & 4963 & 2793 & 1450 & 6407 \\
\hline & 11 & 18583 & 25124 & 14139 & 7338 & 32433 \\
\hline & $\mathrm{A}$ & 11835 & 16000 & 9005 & 4673 & 20655 \\
\hline \multirow{9}{*}{ B } & 1 & -58 & -76 & -48 & -22 & -101 \\
\hline & 2 & 15591 & 20420 & 12892 & 5852 & 27204 \\
\hline & 3 & 26424 & 34607 & 21850 & 9918 & 46106 \\
\hline & 4 & 4094 & 5362 & 3385 & 1537 & 7144 \\
\hline & 5 & 37072 & 48552 & 30654 & 13914 & 64684 \\
\hline & 6 & 44629 & 58449 & 36903 & 16750 & 77870 \\
\hline & 7 & 13456 & 17623 & 11127 & 5050 & 23479 \\
\hline & 8 & 16268 & 21306 & 13452 & 6106 & 28385 \\
\hline & A & 19684 & 25780 & 16277 & 7388 & 34346 \\
\hline \multirow{12}{*}{$\mathrm{C}$} & 1 & 47908 & 63524 & 38552 & 18969 & 84265 \\
\hline & 2 & -42639 & -56537 & -34312 & -16883 & -74996 \\
\hline & 3 & -16689 & -22129 & -13430 & -6608 & -29354 \\
\hline & 4 & -442 & -586 & -355 & -175 & -777 \\
\hline & 5 & -41324 & -54795 & -33254 & -16362 & -72685 \\
\hline & 6 & 22283 & 29546 & 17931 & 8823 & 39193 \\
\hline & 7 & 19618 & 26546 & 17931 & 8823 & 34506 \\
\hline & 8 & -34961 & -46356 & -28133 & -13843 & -61492 \\
\hline & 9 & -35050 & -46476 & -28205 & -13878 & -61650 \\
\hline & 10 & -25434 & -33725 & -20467 & -10071 & -44736 \\
\hline & 11 & 6227 & 8257 & 5011 & 2466 & 10952 \\
\hline & A & -9137 & -12115 & -7352 & -3618 & -16070 \\
\hline \multirow{4}{*}{$\mathrm{D}$} & 1 & -45587 & -60040 & -36738 & -17890 & -78625 \\
\hline & 2 & 40676 & 53572 & 32780 & 15963 & 70156 \\
\hline & 3 & -52748 & -69472 & -42509 & -20701 & - 90977 \\
\hline & 4 & 22283 & 29348 & 17958 & 8745 & 38433 \\
\hline
\end{tabular}


$3^{\text {rd }}$ International Conference On Research In MANAGEMENT AND ECONOMICS

\begin{tabular}{|c|c|c|c|c|c|}
\hline 5 & -45076 & -59367 & -36326 & -17690 & -77744 \\
\hline 6 & -13751 & -18111 & -11082 & -5397 & -23717 \\
\hline 7 & 27040 & 35613 & 21791 & 10611 & 46636 \\
\hline 8 & -39248 & -51692 & -31630 & -15403 & -67693 \\
\hline 9 & 44417 & 58499 & 35795 & 17431 & 76607 \\
\hline 10 & 12029 & 15807 & 9436 & 4282 & 10986 \\
\hline $\mathrm{A}$ & -4997 & -6584 & -4052 & -2005 & -95938 \\
\hline
\end{tabular}

\subsection{Costs from the Effects on the Environment}

Since the additional costs from the effects on the environment were large, that subject needs to be discussed. Construction sites have quite large negative influence on local environment and environment in general. They produce a large number of negative effects of which some stay permanently. In recent years, with large impact of rising environmental consciousness, a large number of legislations and rules have been established in Serbia, but since the construction of residential buildings (as one of the oldest human activities) is impossible to stop, the costs for the impacts on the environment through various taxes has risen. Besides that, for not working in between the approved parameters in legislations, many high priced penalties are often received. Construction activity uses natural resources trough incorporated materials but the major problem is generating waste and the amount of waste generated by construction and demolition activity is substantial. It is a genneral approximation that up to $30 \%$ of the ammount of waste in the cities landfils is comprised of construction waste with an estimation that the ammount from demolition takes the $2 / 3$ of it. Since in reality there aren't any free spaces in cities and the construction of residential buildings is mostly being done on the land comprised of several connected parcels but houses that need to be removed, demolition creates more waste that construction process itself. It is a usual practice that the trees on the site get removed, especially for the creation of the required number of parking spaces, but also the Investor or the architect may request that. Also the activity on construction sites may damage trees within its vicinity, especially if it's on the border and it prevents an obstacle from unloading materials by autocrane or pumping concreete by autopumps. Trees being important natural elements in the urban landscape purify the air and retain moisture, also provide shades and shelter for birds. Construction sites are often related to increase of heat in summer months in the surrounding area since the construction materials, and especially concreete, absorb large quantities of heat from the sun and act as a reservoir which heats up the air around it. Other very important negative efect is a pollution of air by the generation of dust, especially during the demolition process when large quanities are released in the area which can not be witigated without trees. During the escavation dust particles from the escavated earth are carried by wind from the backs of trucks if not properly protected. Other negative effcts include greenhouse gas emissions which have impact on ozone exhausting. Contamination of land and water and damaging of the public drainage system is done by use of a many of pollutant fluids that may spoil the land (paints, solvents, oils and washing water from construction sites). It can potentially create harmful chemical solutions that are toxic in its nature. Direct evacuation to the sewage system is inconvenient and forbidden because they may damage pipes but in practice it is a standard way of work. During 


\section{MANAGEMENT AND ECONOMICS}

the rain season it clogges the sewage pipes and high maintenance costs arise. It is often accompanied by mud in streets which come from the tyres of trucks during the escavation process if they are not cleaned when leaving the construction area which increases the maintenance costs for public space and private properties. Noise is a special problem that can not be removed since it comes from pneumatic hammers, compressors, concrete mixers, operating machinery, communication among workers, etc. Since construction sites for residential buildings are in the middle of residential areas they affect the right to silence, comfort and can reduce health of resident and visiting population and have a large influence on normal activity of near by schools, hospitals and other economic activity, depending on their surroundings. The solution lies in planning for eco-efficient construction project management where to the basic objectives of project - time, quality and cost, other objectives are added biodiversity, resource depletion and harmful emissions with their influence on health (Figure 2)[8].

Figure 2: Difference between CPM and Eco-Efficient CPM

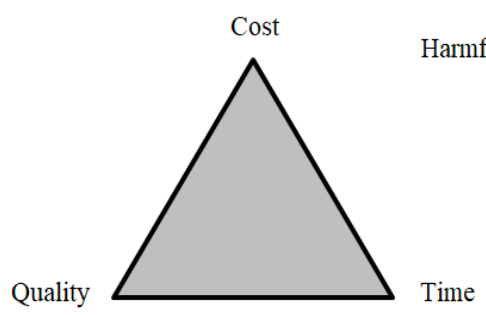

Construction Project Management

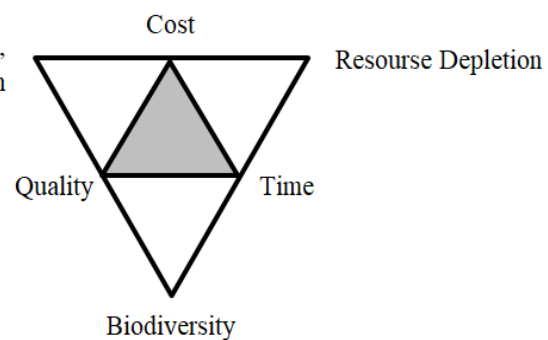

Eco-Efficient Construction Project Management

\section{Results and discussion}

\subsection{Results from the Assessment of observed Residential buildings}

Analyzing the Table 3 we can assess the losses and gains during the process of construction projects according to the given groups of residential buildings (Table 5).

Table 5: Difference between planned cost and actual final cost of construction activities, $€, \%$

\begin{tabular}{|c|c|c|c|c|c|c|c|c|}
\hline \multirow{3}{*}{ 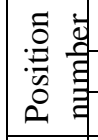 } & \multicolumn{8}{|c|}{ Residential building group } \\
\hline & \multicolumn{2}{|c|}{$\mathrm{A}$} & \multicolumn{2}{|c|}{$\mathrm{B}$} & \multicolumn{2}{|l|}{$\mathrm{C}$} & \multicolumn{2}{|c|}{$\mathrm{D}$} \\
\hline & $€$ & $\%$ & $€$ & $\%$ & $€$ & $\%$ & $€$ & $\%$ \\
\hline 1 & 2 & 3 & 4 & 5 & 6 & 7 & 8 & 9 \\
\hline 1 & -114965 & 11.73 & +303 & 0.02 & -253219 & 10.52 & +238880 & 6.23 \\
\hline 2 & -63324 & 6.70 & -81959 & 5.44 & +225367 & 9.21 & -213147 & 5.56 \\
\hline 3 & -58134 & 6.00 & -138904 & 9.32 & +88209 & 3.67 & +276406 & 7.14 \\
\hline 4 & +5767 & 0.60 & -21522 & 1.42 & +2335 & 0.10 & -116768 & 3.05 \\
\hline 5 & -159450 & 16.12 & -194876 & 13.17 & +218420 & 9.14 & +236204 & 6.08 \\
\hline 6 & -3005 & 0.32 & -234601 & 15.41 & -117775 & 4.83 & +72059 & 1.88 \\
\hline 7 & -76416 & 7.94 & -70735 & 4.74 & -103692 & 4.39 & -141691 & 3.66 \\
\hline 8 & -14691 & 1.53 & -85515 & 5.54 & +184784 & 7.72 & +205665 & 5.33 \\
\hline 9 & -82732 & 8.50 & - & - & +185260 & 7.66 & -232749 & 6.01 \\
\hline 10 & -19283 & 1.94 & - & - & +134433 & 5.66 & -52541 & 1.36 \\
\hline
\end{tabular}



MANAGEMENT AND ECONOMICS

\begin{tabular}{|l|c|c|c|c|c|c|c|c|}
\hline 11 & -97617 & 10.02 & - & - & -32912 & 1.37 & - & - \\
\hline \multicolumn{8}{|c|}{ Arithmetical mean value } \\
\hline A & -62168 & 6.42 & -103476 & 6.88 & +48292 & 2.01 & +27232 & 0.71 \\
\hline
\end{tabular}

The results show us that the smaller scale projects have achieved losses according to the projected cost in the preparation phase (Project Planning phase) of the project cycle with only two projects with insignificant gains. Construction managers for residential buildings in group A after completing construction activities have achieved lost on average with $6.42 \%$ towards the planned cost, with the biggest one of $16.12 \%$, and one project out of 11 was completed without loss with only $0.60 \%$ in the plus. Projects for residential buildings in group B have even larger average loss with $6.88 \%$, while the biggest one was $15.41 \%$. They also have one project in plus out of eight but with only $0.02 \%$ which barely stands out. Both groups have in general more than half of projects having losses bigger than $5.00 \%$ of the planned amount of financial means for their projects. On the other side, larger scale projects, even with in some cases higher individual loss as in terms of amount of money, have been managed more seriously. Residential buildings in group $\mathrm{C}$ have achieved gains after completing construction activities in average $2.01 \%$ with only three out of eleven of observed projects achieving losses. The biggest loss was $10.52 \%$ and the biggest gain was $9.21 \%$. Finally, projects for residential buildings in group D also have positive results as average, although only with $0.71 \%$. Half of the project were run successfully with the best one with $6.23 \%$ in plus, and half unsuccessfully with $6.01 \%$ in minus. From the general look on the data and the results, and also with the experience within the construction industry in Serbia, the conclusion draws it selves that the smaller scale projects in groups A and B weren't seriously planned in the stage of preparation for the construction activities. The companies approached the projects on the intuition and experience from previous construction projects, without hiring qualified project managers. On the other side projects in groups $\mathrm{C}$ and D were executed mostly by companies that have a long history of properly executed projects and that led to financial gain at the end of them.

On the account of the individual cost types (Table 4), as presumed the largest amount of additional finances is focused on procuring materials. If properly planned it reduces the cost of other segments, especially the amount for the wages for workers, because there won't be a loss in time due to slow performance in works. It'll also reduce operating costs of machinery and equipment since the ammount of time for their usage will be shortened. It points out that the key planning ellement is propper planing focused around material procuring.

It is notable that on most of the projects there wasn't a proper approach to the costs from the effects on the environment which have significant impact on the budget, from $30 \%$ to $55 \%$ of overhead costs. The cost mostly came from unplanned payments for hard waste and on engagement of workers on its collecting. Some companies overlooked the demolition process in total and necessary activity for it. Many of the expenses went on paying various environmental taxes and paying penalties for improper waste management, water evacuation to a sewer system and creation of dust. A large number of penalties were for dirtying streets. The main problem was noise 
complaints from the residents in surrounding buildings, especially at communication among workers. Working on weekends brought most of them. As mantione earlier, introducing eco-efficient construction project management into company's management policy would result into reducing impact on the environment, and thus reducing cost of the construction activities in that segment.

\subsection{Problems Related to Inadequate Project Planning at the Stage of Preparation}

All of the additional costs came from the delays that came out of risks which appeared as results of nonexistent or improper construction project management. From the given a following conclusion can be derived about the causes of delays related to construction companies which caused the excess cost: inadequate Contractor experience, lack of or overused project management staff and shortage of technical staff, lack of planning and control from the Contractor, slow decision making process, limited authority among decision makers, fluctuating labour, materials and equipment availability. Also in some cases a lack of coordination with Subcontractors and poor choice and scheduling of the same amounted to reduced productivity levels.

At the stage of preparation hiring an experienced project manager, especially if he has working knowledge of FIDIC, can reduce additional costs by timely anticipating possible risks and schedule their mitigation and the mitigation of eventual changes that might occur out of them. The project needs to be broken down adequately to cover all necessary work types. The correct amount of man hours need to be calculated and proper time planning for the acquiring materials needs to be determined. Problems come out when most of that hasn't been completed in propper time and then improvisations come in which increases the cost of construction activities. One of important thing is also correct budgeted planning with planned reserve for possible mistakes from the lack of experience of project manager, since there are no two same construction projects in the world. The gains which appear on many observed projects (Table 3) are related to over budgeting on account "just in case something goes wrong" and "better safe than sorry". The cost of construction activities needs to be calculated on the measure of normal work hours needed for some task to be completed, adjusted to the possibilities of a company which is conducting those activities, in terms of needed workforce, materials and equimpment. According to the results in Table 5, if there aren any available data for a type of work, a coressponding activity can be utilised with an increase in costs of up to $7 \%$. There is a widely used practice among small and especially medium sized construction companies in Serbia where they reduce price of cost of construction activities down to zero in earning margins. In that way they give the lowest price with only covering the planned expenses of direct costs, and they win contracts. Their earnings come from tax refund law on purchased construction materials, however,without proper calculating of possible risks those earnings melt away in front of additional costs that come up during the construction period. 


\section{Conclusion}

The seriousness of the problem of improper planning before the start of a construction project leads to multiple organizational and technological risks which can significantly increase the final cost of construction activities. Methods for prevention of their appearance or for preparedness for their inevitable appearance can be achieved through following tasks: identifying the factors which can organizational and technological risks during the period of construction activities; studying the dynamics of accumulation of labour, material, operational, managerial risks for organizational and technological reasons in the process of construction of residential buildings; assessing the impact of individual risk groups and total risks on the reliability of the construction and installation process; identifying and evaluating the dynamics of changes in the costs of restoring the loss of construction and installation reliability under the influence of organizational and technological risks; identify trends and the mutual influence of the level of reliability of the construction process and unit costs of construction activities, depending on the volume of production and the length of the period of construction; develop a methodology for strategic management of organizational and technological risks at the stage of production preparation; and indentifying and prioritizing the environmental aspects and impacts relevant to each construction activity and creating a Construction Site Environmental Management Plan which contains a detailed plan on how and when each problem should be dealed with, required recourses, with marked responsibility and a monitoring plan.

\section{References}

[1] Project Management Institute (2017), A Guide to the Project Management Body of Knowledge (PMBOK® Guide)-Sixth Edition, Chapter 5

[2] Project Management Institute (2016), Construction Extension to the PMBOK® Guide

[3] National Academy of Engineering, (2004). The Engineer of 2020: Visions of Engineering in the New Century; Report; The National Academies Press: Washington, DC, USA

[4] Baldwin, J., James, M., Harold, R and Harris, R., (1971). Causes of Delay in Construction Industry, Journal of the Construction Division, ASCE:177-187

[5] Hall, E. M. (1998)., Managing Risk: Methods for Systems Development, Addison Wesley

[6] Laws, D. Loeber, A., (2011), Sustainable development and professional practice, Proceedings of the ICE-Engineering Sustainability, 164, 25-33.

[7] Kaka, A. and Price, A.D. (1991), Relationship between Value and Duration of Construction Projects, Construction Management and Economics, 9, 383-400.

[8] Ilse, N., Rothbucher T., Bastos Costa D., (2017), Adoption of environmental practices on construction sites, Ambient. constr. vol.17 no.4 Porto Alegre 